\title{
CERVICAL CANCER AND ITS SCREENING: A CROSS-SECTIONAL STUDY AMONG MARRIED WOMEN IN SANKHU, KATHMANDU
}

\author{
Rijal $S^{1^{*}}$, Rijal $A^{2}$, Deo $S^{3}$
}

\section{Affiliation}

1. Master in Child development and Gender Socialiazation, Lecturer in Om Health Campus, Gopikrishna Nagar, Chabhil, Kathmandu.

2. Lecturer in Everest College of Nursing, Tinkune, Kathmandu

3. Associate Professor, Department of Clinical Pharmacology, Maharajgunj Medical Campus, Institute of Medicine, Kathmandu

\section{ARTICLE INFO \\ Article History \\ Received : 4 March, 2018 \\ Accepted : 25 November, 2018 \\ Published : 31 December, 2018}

(C) Authors retain copyright and grant the journal right of first publication with the work simultaneously licensed under Creative Commons Attribution License CC - BY 4.0 that allows others to share the work with an acknowledgment of the work's authorship and initial publication in this journal.

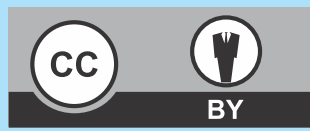

ORA 82

DOI: $10.3126 /$ bjhs.v3i3.22167

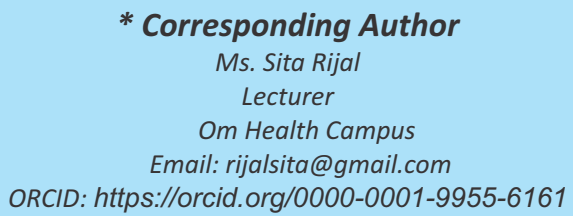

\section{Citation}

Rijal S, Rijal A, Deo S. Cervical Cancer And Its Screening: A Crosssectional Study among Married Women in Sankhu, Kathmandu. BJHS 2018;3(3)7: 519-523

\section{ABSTRACT}

\section{Introduction}

Cervical cancer ranks as the most frequent cancer among women between 15 and 44 years of age in Nepal. It is one of the preventable cancer. The effectiveness of cervical cancer screening depends to a great extent on the level of awareness.

\section{Objective}

The objective ofstudy is to explore the knowledge regarding cervical cancer and its screening and use of pap smear test as a screening tool amongst the married women in Sankhu, Kathmandu.

\section{Methodology}

A descriptive, cross-sectional study was conducted in April 2017 using interview guided questionnaire. One hundred and ten married women aged 30-60 years were included in the study to assess knowledge regarding cervical cancer and its screening. Among 110, 85 were eligible for screening tests but only 65 consented and participated in pap smear tests. Multiple regression analysis was used to find out the association of knowledge and practice of cervical cancer and its screening with various variables.

\section{Results}

Out of 110 participants, $54.5 \%$ belong to age groups $30-40$ and mean age was 41.50 years. Though, $62.5 \%$ knew about cervical cancer and $26.8 \%$ knew about pap smear test, only $22.7 \%$ participants had undergone cervical cancer screening test previously. Multivariateregression analysis showed that the lower education level was significantly associated withpoor knowledge on cervical cancer (Odd ratio: 1.71, 95\% Confidence interval 1.10-2.66; $p=0.01$ ) and poor practice of its screening (Odd ratio 1.92, 95\% Confidence interval 1.27-2.89; $p=0.00$ ).

\section{Conclusion}

The study reveals that education level has significant effect on knowledge and practice of screening tests.

\section{KEYWORDS}

Cervical cancer, Married women, Pap smear test 


\section{INTRODUCTION}

Cervical cancer ranks as the most frequent cancer among women between 15 and 44 years of age in Nepal. About $2.0 \%$ of women in the general population are estimated to harbour cervical Human Papilloma Virus(HPV)-16/18 infection at a given time, and $80.3 \%$ of invasive cervical cancers are attributed to HPVs 16 or $18 .^{1-3}$

It is one of the preventable cancer which can be prevented by early detection and treatment. Cervical cancer screening programmes such as Pap smear test, visual inspection with acetic acid application(VIA) and HPV screening test are established as the most effective approach to control cervical cancer. ${ }^{4,5}$ The effective age for the pap smear test is considered as 15-44 years. ${ }^{6}$ However, the screening programmes is underutilized in most of the developing countries, including Nepal. ${ }^{7}$ The main barriers to underutilization of screening tests are poor information on availability, accessibility screening tests, lack of affordability of screening tests (pap smear test, HPV vaccine,VIA test), unavailability of the screening tests at most of the health centers. $^{7-9,}$ Numerous studies have been conducted in different countries to evaluate the awareness level of cervical cancer, contributing and risk factors, cervical screening test, the attitude towards it as well as the preventative practices. ${ }^{10-12}$

The effectiveness of cervical cancer screening depends to a great extent on the level of awareness. Therefore, this study is conducted with the aim to gather information regarding the knowledge and practice of cervical cancer screening in women residing in one of the ancient town of Kathmandu district named Sankhu.

\section{Objectives of the study:}

To assess knowledge on cervical cancer and pap smear tests, HPV vaccine

\section{To assess practice on pap smear test}

To associate knowledge of cervical cancer and practice of cervical cancer screening with socio-demographic variables.

\section{METHODOLOGY}

A descriptive cross-sectional research design was used to assess knowledge and practice regarding cervical cancer and its screening among married women of Sankhu municipality. The study was conducted in April 2017. Sample size 110 was estimated by using formula $\left(n=z^{2} p q / d^{2}\right)$. All the married women meeting inclusion criteria were included in the study till estimated sample size was met. One hundred and ten married women participated in interview related to cervical cancer and its screening. Though 85 were eligible for the pap smear test, it was performed among 65 participants and 20 were excluded. Exclusion criteria were stated as age groups below 30 and above 60 years, pap smear test done within 3 years, women on menstruation and postnatal period. The study was conducted in Cervical cancer screening camp as organized by CISWA, Shankarapur Hospital in coordination with the local community of Sankhu. Semi structure questionnaire consisted of 3 parts: part one as information related to socio-demographic data, part two as knowledge on cervical cancer, pap smear test and HPV vaccine and part three as practice relate to cervical cancer screening (pap smear test, VIA test). Permission was taken from the Chairperson of Sankhu, Municipality. Verbal and written consent was taken from each participant before conducting interview and Pap smear test.Confidentiality of the respondents was maintained. The study was approved by research committee of Shankharapur hospital and formal permission was taken from each concerning organization. The data collected from the interview was coded and data analysis was done by using SPSS version 22 . Descriptive (mean, standard deviation) and inferential analysis (regression analysis) were used for data analysis.

\section{RESULTS}

The mean age of the participants was 41.50 years, $46(41.8 \%)$ were of Brahman ethnic group, 93(83.0\%) of the participants were married for more than 9 years, 35.5(39.1 $\%)$ had 3 children, 44(40.0\%) were illiterate and more than half 64(58.9\%) were engaged in household work (Table 1 ).

Table 1: Socio-demographics variables $n=110$

\begin{tabular}{lc} 
Variables & $\begin{array}{c}\text { Frequency } \\
\text { (Percentage) }\end{array}$ \\
\hline Age (in years) & $60(54.5)$ \\
$30-40$ & $29(26.4)$ \\
$41-50$ & $21(19.1)$ \\
$51-60$ & \\
Ethnicity & $46(41.8)$ \\
Brahmin & $41(37.3)$ \\
Chhetri & $23(20.9)$ \\
Janajati* & \\
Educational level & $44(40.0)$ \\
Illiterate & $23(20.9)$ \\
Primary & $24(21.8)$ \\
Secondary & $11(10.0)$ \\
Higher secondary & $8(7.3)$ \\
Bachelor & \\
Occupation & $64(58.9)$ \\
Home maker & $15(13.4)$ \\
Service & $13(11.6)$ \\
Business & $18(16.3)$ \\
Agriculture & \\
Duration of Marriage & $8(7.3)$ \\
$3-6$ years & $10(9.1)$ \\
$6-9$ years & $92(83.6)$ \\
$\geq 9$ years & \\
Parity & $8(7.3)$ \\
No child & $20(18.2)$ \\
1-2 children & $43(39.1)$ \\
$\geq 3$ children & $39(35.5)$ \\
& \\
\hline & \\
\hline & \\
\hline
\end{tabular}

Mean age \pm SD $\quad 41.50 \pm 9.18$

*(Magar/Gurung/Tamang) 
Thirty two (45.8\%) stated that family member/friends provided information about cervical cancerand16 (53.3\%) stated that health personnel provided information about pap smear test. (Table 2).

$\begin{array}{lc}\begin{array}{l}\text { Table 2: Participants' information about Cervical Cancer } \\ \text { and its Screening }(\mathrm{n}=110)\end{array} \\ \begin{array}{ll}\text { Variable } \\ \text { Heard about cervical cancer }\end{array} & 70(62.5) \\ \begin{array}{l}\text { Sources of information* } \\ \text { Family member/friend }\end{array} & 32(45.8) \\ \text { Health professional } & 10(14.3) \\ \text { Media } & 25(35.7) \\ \text { School } & 3(4.3) \\ \text { Heard about pap smear test } & 30(26.8) \\ \text { Sources of information* } & \\ \text { Family member/friend } & 5(16.7) \\ \text { Health professional } & 16(53.3) \\ \text { Media } & 9(30.0) \\ \text { Heard about HPV vaccine } & 5(4.5)\end{array}$

*multiple response questions

Values are presented as correct response

Variousquestions related to cervical cancer like causes, risk factors, sign and symptoms, preventive measures are shown in Table 3.

Table 3: Participants' Knowledge regarding Cervical Cancer $n=110$
Variables Frequency (Percentage)

\section{Causes}

Risk factors*

Family history

Poor hygiene

Early pregnancy

Having multiple sex partners

Early marriage

Bearing more children

Tobacco smoking/chewing

Poor nutrition

Prolong use of Contraceptives

Sign/Symptoms*

Abnormal vaginal bleeding

Pain in lower abdomen

Abnormal/offensive vaginal discharge

Bleeding after intercourse

Abnormal bleeding after menopause

Menstrual bleeding longer and heavier

Cervical cancer can be prevented

Preventive Measures*

Personal hygiene

Pap Smear test

No smoking

Prevention and treatment of urinary

tract infection. $13(11.8)$

$29(53.7)$

24(44.4)

$15(27.8)$

$15(27.8)$

$12(22.2)$

$10(18.5)$

$10(18.5)$

$9(16.7)$

$4(7.4)$

22(61.1)

15(41.7)

14(38.9)

7(19.4)

5(13.9)

4(11.1)

$39(35.5)$

$19(59.4)$

$9(28.1)$

$7(21.9)$

6(18.8)

$4(12.5)$

$3(9.4)$

$3(9.4)$

No early marriage

No early pregnancy
The knowledge on pap smear test and HPV vaccine are stated in table 4.

$\begin{array}{ll}\begin{array}{l}\text { Table 4: Participants' Knowledge on Pap smear test and } \\ \text { HPV vaccine } n=30 \\ \text { Variable }\end{array} & \text { Frequency (Percentage) } \\ \text { Purpose of Pap smear test } & 30(27.3) \\ \text { Appropriate time for Pap smear test } & 12(10.9) \\ \text { Appropriate age for Pap smear test } & 4(3.6) \\ \text { Right Interval between Pap smear test } & 2(1.8) \\ \text { Appropriate age for HPV vaccine } & 5(4.5) \\ \text { Course of HPV vaccination } & 2(1.8)\end{array}$

\section{Values are presented as correct response}

Table 5: Participants' Practice on screening for Cervical

Cancer $n=110$

Variable

Frequency (Percentage)

$\begin{array}{ll}\text { Screening for cervical cancer" } \\ \text { Yes } & 25(22.73) \\ \text { No } & 85(77.27) \\ \text { Type of test done" } & \\ \text { Pap smear test } & 20(80) \\ \text { VIA test } & 5(20) \\ { }^{a} n=70 & \\ { }^{b} n=25 & \end{array}$

Table 6: Socio-demographic characteristics that correlate to the knowledge about cervical cancer and practice of screening tests $n=110$.

\begin{tabular}{|c|c|c|c|c|}
\hline \multirow{2}{*}{ Variables } & \multicolumn{2}{|c|}{ Knowledge (>50\%) } & \multicolumn{2}{|c|}{ Practice(Ever screen) } \\
\hline & OR(C) & Pvalue & OR(C) & Pvalue \\
\hline $\begin{array}{l}\text { Age } \\
>30 \text { years }\end{array}$ & $1.17(0.46-2.96)$ & 0.73 & $1.04(0.46-2.37)$ & 0.91 \\
\hline Ethnicity & $1.25(0.54-2.90)$ & 0.59 & $1.05(0.49-2.24)$ & 0.90 \\
\hline Religion & $0.35(0.04-2.62)$ & 0.31 & $0.32(0.07-1.47)$ & 0.14 \\
\hline $\begin{array}{l}\text { Numberof } \\
\text { children }\end{array}$ & $0.58(0.28-1.21)$ & 0.15 & $2.11(0.94-4.76)$ & 0.06 \\
\hline $\begin{array}{l}\text { Educationa } \\
\text { I Level }\end{array}$ & $1.71(1.10-2.66)$ & $0.01^{*}$ & $1.92(1.27-2.89\}$ & $0.00^{*}$ \\
\hline Qceupation & $0.97(0.55-1.70)$ & 0.93 & $0.73(0.43-1.24)$ & 0.24 \\
\hline Family type & $0.57(0.221 .51)$ & 0.26 & $0.42(0.16-1.07)$ & 0.07 \\
\hline
\end{tabular}

\section{*significant at $\mathrm{p}<0.05$}

\section{DISCUSSION}

The present study was conducted among married women to assess knowledge and practice on cervical cancer and its screening and also to perform Pap smear test among the participants. Among 110 participants, only 70(62.5\%) participants had heard about the cervical cancer and rest were unknown about cervical cancer. Similar, finding was reported by the study done in Nepal, Ethopia which showed that majority (78.7\%) heard about it. ${ }^{10,11}$ Similar, finding was

\section{*multiple response question}


reported in North Korea. ${ }^{12}$ The reason for the majority of the participants heard about cervical cancer may be the awareness programs conducted previously in Sankhu. Contrast to it, majority of the participants (88.4\%) were unknown about the cause of cervical cancer. This finding was consistent with that found in similar studies done in Kenya and Nepal. ${ }^{13,14,15}$

The most common risk factor was found to be family history $(53.7 \%)$ in this study. But, contrast finding was reported in the study done in India which showed multiple sexual partners as major risk factor. ${ }^{16}$

Abnormal vaginal bleeding was the commonly (61.1\%) mentioned symptom among study participants. This finding is similar to study done in India. ${ }^{16}$ When asked about whether cervical cancer is preventable or not: $34.8 \%$ of the participants said cervical cancer is preventable. Similar finding was reported by study conducted in Nigeria where $30.0 \%$ replied cervical cancer as preventable in nature. ${ }^{17}$

In our study, $26.8 \%$ had heard of Pap smear test as cervical cancer screening test. But this was contrast to that found in study done in Kathmandu, Nepal where $68.6 \%$ have heard of cervical cancer screening. ${ }^{18}$

To our questions regarding the knowledge of the Pap smear test, only $10 \%$ knew the meaning, $27.3 \%$ replied on its purpose, $10.9 \%$ identified the best time for the test and only $3.6 \%$ knew the appropriate age for test. Similar findings were reported by Shrestha J et.al, where $16.57 \%$ knew the meaning, $10.36 \%$ knew about eligibility of screening, and only $1.58 \%$ knew about screening interval. ${ }^{18}$ Contrary to this finding was the study of Shrestha and Dhakal where $25.0 \%$ knew the correct age to start screening. ${ }^{19}$ Among them, $4.5 \%$ and $18.2 \%$ had VIA (visual inspection with acetic acid) and Pap smear test done. The finding is inconsistent with the finding of study done in Ruvuma which showed $2.9 \%$ and $11.3 \%$ mentioned Pap smear and VIA as the screening test for cervical cancer respectively. ${ }^{20}$

Only $4.5 \%$ of the respondents were aware about the HPV vaccination and only $1.8 \%$ knew the dose of vaccine. Similar finding was noted in a study done in Nepal and India where only $3 \%$ and $2.8 \%$ of the women had heard of HPV vaccine. ${ }^{18,19,21}$

On asking about ever screen for cervical cancer, $22.73 \%$ had undergone screening. Contrasts to it, $32.7 \%$ were screed for cervical cancer as reported in the study done in Nigeria. ${ }^{22}$ Another study done in Mangalore reveled that only 7.2\% had ever undergone pap smear test which is contrast to the finding of the study. ${ }^{23}$

\section{REFERENCES}

References

1. ICO Information Centre on HPV and Cancer. Nepal Human Papillomavirus and Related Cancers, Fact Sheet 2017. Available from: http://www.hpvcentre.net/statistics/reports/NPL_FS.pdf

2. Trottier $\mathrm{H}$ and Franco $\mathrm{EL}$. The epidemiology of genital human papillomavirus infection. Vaccine 2006; 24: 1-15 DOI: 10.1016/ j.vaccine.2005.09.054

3. Sherpa AT, Karki BS, Sundby J, Nygard M, Franceschii S and Clifford
Among eligible participants 85(77.27\%), majority 65(76.5\%) consented and participated for the Pap smear testing. This was contrast with the study done in Southeast Nigeria where Screening up take was only $0.6 \%$ and $10.36 \%$ were eligible in the study done in Nepal. ${ }^{13,16,17,23}$

On multi variant regression analysis, educational level was the sole predictor of knowledge regarding cervical cancer and practice of cervical cancer screening $(p<0.05)$. It may be because of the exposure of women to the media, health personnel and motivation for better practice. Similar finding was noted in study done in India, Nepal, and Kuwaiti. ${ }^{16,19,24}$

\section{CONCLUSION}

The study findings revealed that most of the participants' had inadequate information on cervical cancer and its screening. Though, majority of the women had never gone for pap smear test previously, however, they participated in the cervical cancer screening camp i.e. in pap smear test and results was found to be normal. As mass media was the second common source of information, this could be used to raise the awareness of the women to promote early detection. There is a need for community-based awareness programs to empower the women about cervical cancer and its screening.

\section{RECOMMENDATIONS}

This study recommends initiating proper strategies for conduction of awareness programme among the married women on cervical cancer and its screening from the grassroots level. There is need of low costs screening tests or free availability of screening tests in order to prevent cervical cancer.

\section{LIMITATION OF STUDY}

Study cannot be generalized as the sample size is small and convenient sampling technique is used.

\section{ACKNOWLEDGEMENT}

We acknowledge the financial help received from Civil Service Wives' Association (CISWA). We would like to thank the hospital administration team of Shankarapur Hospital, Sankhu Municipality and the concerned people involved in the study.

\section{CONFLICT OF INTEREST}

We declare no conflict of interest.

G. Population Based Study of Cervical Cancer Screening in Bharatpur, Nepal.Journal of Manmohan Memorial Institute of Health Sciences 2015;1(4):3-8. DOI http://dx.doi.org/ 10.3126/ jmmihs.v1i4.11994

4. Sankaranarayanan R, Nene BM, Dinshaw K, Rajkumar R, Shastri S, Wesley $R$, et al. Early detection of cervical cancer with visual inspection methods: a summary of completed and on-going studies in India. SaludPublica de Mexico 2003; 45 (12): 274-82.

5. Shastri S, Dinshaw K, Amin G, Goswami S, Patil S, Chinoy R, et al. Concurrent evaluation of visual, cytological and HPV testing as 
screening methods for the early detection of cervical neoplasia in Mumbai, India. Bulletin of the World Health Organization 2005; 83 (3): 186-94.

6. World Health Organization (WHO) (2017). Strategic framework for the comprehensive control of cancer cervix in South-East Asia Region. Available from: http://apps.who.int/iris/bitstream/ 10665/152098/1/9789290224723-MRH.pdf

7. Maseko FC, Chirwa ML, Muula AS. Underutilization of cervical cancer prevention services in low and middle income countries: a review of contributing factors. Pan African medical journal 2015; 21:231

8. Sankaranarayanan R, Budukh A, Rajkumar R. Effective screening programs for cervical cancer in low- and middle-income developing countries. Bulletin of the World Health Organization. 2001; 79 (10):954-62.

9. Musmar SG. Pattern and factors affecting Pap smear test in Nablus, a retrospective study. Middle East Journal of Family Medicine. 2004; 4(4).

10. Pandey RA. And Karmacharya E.Cervical cancer screening behavior and associated factors among women of UgrachandiNala, Kavre.Nepal.Eur J Med Res 2017; 22:32. DOI10.1186/s40001-0170274-9

11. Getahun F, Mazengia F, Abuhay M, Birhanu Z. Comprehensive knowledge about cervical cancer is low among women in Northwest Ethiopia. BMC Cancer 2013; 13 (2).

12. Nguyen TT, Song IC, Taylor R, et al. Knowledge, Attitude and Practice (KAP) Concerning Cervical Cancer and Screening among Rural and Urban Women in Six Provinces of the Democratic People's Republic of Korea. Asian Pacific J Cancer Prev 2011;12:3029-33.

13. Rositch AF, Gatuguta A, Choi RY, Guthrie BL, Mackelprang RD, Bosire R, Manyara L, Kiarie JN, Smith JS, Farquhar C. Knowledge and Acceptability of Pap Smears, Self-Sampling and HPV Vaccination among Adult Women in Kenya. PLoS ONE 2012; 7(7): e40766. DOI 10.1371/journal.pone.0040766

14. Shrestha A. Awareness of cervical cancer and screening among rural Nepalese women. Journal of Clinical Oncology 2017;35(15): 1553-1553. DOI 10.1200/JCO.2017.35.15_suppl.1553
15. Khadka K, Shah SK, Sanal TS, Mathias J, Upadhayay A, Ghimire $\mathrm{R}, \mathrm{Ghimire} \mathrm{S}$. Knowledge and Awareness about Cervical Cancer Screening and HPV Vaccine among Females Aged 15-49 Years in Rukum District of Nepal. AmericanJournal of Cancer Prevention 2017; 5(1); 10-16. DOI10.12691/ajcp-5-1-2

16. Bansal AB, Pakhare AP, Kapoor N, Mehrotra R, and Kokane AM. Knowledge, attitude, and practices related to cervical cancer among adult women: A hospital-based cross-sectional study. J Nat SciBiol Med 2015; 6(2):324-328.DOI 10.4103/0976-9668.159993

17. Eze JN, Umeora OU, Obuna JA, Egwuatu VE, Ejikeme BN. Cervical cancer awareness and cervical screening uptake at the Mater Misericordiae Hospital, Afikpo, Southeast Nigeria. Ann Afr Med 2012;11:238-43. DOI 10.4103/1596-3519.102856

18. Shrestha J, Saha R, Tripathi N. Knowledge, Attitude and Practice regarding Cervical Cancer Screening Amongst Women visiting Tertiary Centre in Kathmandu, Nepal. Nepal Journal of Medical sciences 2013;2(2):85-90.DOI http://dx.doi.org/10.3126/ njms.v2i2.8941

19. Shrestha S, Dhakal P. Knowledge, Attitude and Practice Regarding Cervical Cancer Screening Among Women Attending a Teaching Hospital, Bharatpur, Chitwan. J FamReprod Health 2017; 11(1): 18-23.

20. John J. Knowledge, attitude, practice and perceived barriers towards screening for premalignant cervical lesions among women aged 18 years and above, in songea urban, Ruvuma 2011. Retrieved from: http://ihi.eprints.org/962/1/muhas_(39).pdf

21. Assoumou SZ, Mabika BM, Mbiguino AN, Mouallif M, Khattabi A, Ennaji MM. Awareness and knowledge regarding of cervical cancer, Pap smear screening and human papillomavirus infection in Gabonese women. BMC Women's Health. 2015; 15 (37).

22. Ahmed SA, Sabitu K, Idris SH, and Ahmed R. Knowledge, attitude and practice of cervical cancer screening among market women in Zaria, Nigeria Niger Med J2013; 54(5): 316-319. DOI 10.4103/03001652.122337

23. Harsha Kumar H and Tanya S. A Study on Knowledge and Screening for Cervical Cancer among Women in Mangalore City. Ann Med Health Sci Res 2014; 4(5): 751-756. DOI 10.4103/2141-9248.141547

24. Sairafi MA and Mohamed FA. Knowledge, attitudes and Practice related to cervical cancer screening among Kuwaiti Women. Med PrincPract 2009; 18:35-42. DOI 10.1159/000163044 